1 George Institute for Global Health, University of Oxford, UK

2 NHS Lothian, University of Edinburgh, UK

3 Cambridge University Hospitals, NHS East of England, Cambridge, UK

4 Julius Center for Health Sciences and Primary Care, University Medical Center Utrecht, Utrecht University, The Netherlands

5 George Institute for Global Health, University of New South Wales, Australia

6 Department of Epidemiology, Johns Hopkins University, Baltimore MD, USA

v1kwomer@ed.ac.uk Cite this as: BMJ 2020;370:m2870 http://dx.doi.org/10.1136/bmj.m2870 Published: 20 July 2020

\section{Covid-19: Male disadvantage highlights the importance of sex disaggregated data}

\author{
Kate Womersley, ${ }^{1,2}$ Katherine Ripullone, ${ }^{1,3}$ Sanne AE Peters, ${ }^{1,4}$ Mark Woodward ${ }^{1}$, 5, 6
}

Although covid-19 is a new and emerging disease, it could be one of the best understood in terms of its sex disaggregated outcomes. This may sound surprising. Sex disaggregated data (separated for women and men) for confirmed covid-19 cases and deaths are lacking from around half of the most severely affected countries, and most countries are not routinely reporting metrics such as sex or pregnancy status for covid-19 test results, treatment, vaccine trials, or deaths. But even the fact that some countries are considering sex as an important factor in covid-19 outcomes is a significant improvement when compared with the norm of non-sex disaggregated data collection for other infectious and chronic diseases.

Current covid-19 mortality and morbidity data show that women are faring better than men in terms of severity of disease course, likelihood of hospitalisation, and risk of death. ${ }^{1}$ This difference can be seen across nations and socioeconomic groups, while case numbers are similar for men and women. ${ }^{2-4}$ The biological mechanisms and social factors contributing to these differences remain unclear, however.

Collecting sex disaggregated data has both immediate and long term benefits. ${ }^{5}$ With clinical practice around covid-19 continually being reviewed and updated, data from the disease's onset in late 2019 have rapidly improved the quality of care. This could be further refined by sex disaggregated data, which may help our understanding of how sex hormones contribute to different female and male immunological responses. Women's comparably favourable immune response might offer essential insights into treatment and vaccine development. Moreover, steroids and other immunomodulators are being trialled to manage secondary fibrotic damage, and these drugs have different side effects in women and men. ${ }^{6}$ These are some of many important considerations for clinical guidelines on management of covid-19, which suggest that attempts to standardise care should vary according to sex.

A distinction is necessary, however, between sex disaggregated data on outcomes as opposed to exposures. While countries may be making headway collecting sex disaggregated data in the former category, much less reliable data are available for the latter. It is clear-though not well quantified-that women face higher risks of exposure to covid-19 than men. The majority $-70 \%$ - of workers in healthcare and social sectors globally are women, which drives disparities in exposure to, and transmission of, the disease. ${ }^{7}$ Increased exposure to the virus has been exacerbated by widespread reports in the NHS and internationally of unsuitable and unsafe working conditions. ${ }^{8}$ Available personal protective equipment (PPE) is not designed to fit female workers. The small sized reusable masks now being rolled out are used up before larger sizes, yet stock ordering has not accounted for this. $9^{10}$

Data are also missing on the indirect consequences covid-19 has on women, both physically and sociologically. Women's control over their work environment has been undermined as the pandemic has damaged sectors that disproportionately employ women, such as hospitality, retail, and leisure, as well as healthcare. The risk pregnant women face from the disease is not fully understood, and pregnant NHS workers have reported mixed responses from trusts. Some occupational health departments have been overcautious, even paternalistic, in undermining the Royal College of Obstetrics and Gynaecology's guidance that in the first and second trimesters pregnant doctors and nurses should assess for themselves the extent to which they are comfortable with a patient facing role. ${ }^{11}$ Meanwhile, other employers have furloughed pregnant workers without discussion and then not paid their usual salary, despite contractual obligations. $^{12}$

When it comes to testing treatments and vaccines for covid-19, women are likely to suffer differentially, again. Women, particularly those who are pregnant, are routinely excluded from clinical drug trials as their anatomy and physiology are considered "distorting," which allegedly makes trials more complicated to run and results harder to analyse. ${ }^{5}$ For a potentially fatal disease like covid-19, however, remaining ignorant of the sex specific dangers that such treatments and vaccines pose, and the different levels of efficacy they may have in women, is inexcusable. Ongoing randomised controlled trials of vaccines and potentially mitigating drugs must include representative numbers of women and men.

As men appear to be at a disadvantage in terms of covid-19-related morbidity and mortality compared with women, data that take sex into account for this disease have been acknowledged to be urgent, essential, and feasible by researchers, businesses, and governments. While it is concerning that men's health seems to carry more weight than women's when it comes to changing research cultures, we must ensure this pandemic is the necessary event that insists upon future collection of sex disaggregated data as standard. Without this, any analysis is partial. To achieve better health outcomes for all, wider considerations of protection, exposures, management, treatment, clinical outcomes, and consequences-which in the case of covid-19, as with 
many diseases, disadvantages women and men in different ways-must be analysed on the basis of sex.

Competing interests: None declared.

Commissioned, not peer reviewed.

1 ICNARC. Report on covid-19 in critical care. 4 April 2020. https://webcache.googleusercontent.com/search?q=cache:YVPYsW_wOHAl:https://www.icnarc.org/DataServices/Attachments/Download/76a7364b-4b76-ea11-9124-00505601089b+\&cd=2\&hl=en\&ct=clnk\&gl=uk .

2 Epidemiology Working Group for NCIP Epidemic Response, Chinese Center for Disease Control and Prevention. Zhonghua Liu Xing Bing Xue Za Zhi 2020;41:145-51.pmid: 32064853

3 lin JM, Bai P. He W, et al. Gender differences in patients with covid-19: focus on severity and mortality. Front Public Health 2020;8:152. doi: 10.3389/fpubh.2020.00152 pmid: 32411652

4 Institutio Superiore di Sanità. Epidemia covid-19. 12 March 2020. www.epicentro.iss.it/coronavirus/bollettino/Bollettino-sorveglianza-integrata-COVID-19_12-marzo-2020.pdf.

5 Criado-Perez C. Invisible women: exposing data bias in a world designed for men. Chatto and Windus, 2019

6 Felsenstein S, Herbert JA, McNamara PS, Hedrich CM. COVID-19: Immunology and treatment options. Clin Immunol 2020;215:. doi: 10.1016/j.clim.2020.108448 pmid: 32353634

7 WHO. Women in the health workforce. 7 March 2018. www.who.int/hrh/events/2018/womenin-health-workforce/en.

8 Campbell D. Doctors lacking PPE "bullied” into treating covid-19 patients. Guardian. 7 April 2020 www.theguardian.com/world/2020/apr/06/nhs-doctors-lacking-ppe-bullied-into-treating-covid19-patients.

9 Kleinman Z. PPE “designed for women” needed on frontline. BBC News. 28 April 2020. www.bbc.co.uk/news/health-52454741.

10 Pugh R. Covid-19 PPE gender divide: no one-size-fits-all? Medscape. 4 May 2020. www.medscape.com/viewarticle/929860.

11 Royal College of Obstetricians and Gynaecologists. Coronavirus (covid-19) infection and pregnancy. 19June 2020. www.rcog.org.uk/en/guidelines-research-services/guidelines/coronavirus-pregnancy.

12 Maternity Action. Covid-19. https://maternityaction.org.uk/tag/covid-19. 